\section{Is Artemisinin the Only Antiplasmodial Compound in the Artemisia annua Tea Infusion? An in Vitro Study}

\author{
Julia Mouton ${ }^{1}$, Olivia Jansen ${ }^{2}$, Michel Frédérich ${ }^{2}$, \\ Frank van der Kooy ${ }^{3}$ \\ ${ }^{1}$ Natural Products Laboratory, Institute of Biology, Leiden University, \\ Leiden, the Netherlands \\ 2 Laboratory of Pharmacognosy, Department of Pharmacy, Drug \\ Research Center (CIRM), Université de Liège, Belgium \\ ${ }^{3}$ Centre for Complementary Medicine Research, University of \\ Western Sydney, Penrith, Australia
}

\section{Abstract \\ $\nabla$}

In our ongoing investigation into Artemisia annua for the treatment of malaria, we decided to study the possibility that synergism might enhance the efficacy of artemisinin. Our main objective was to test tea infusions and nonpolar extracts prepared from different $A$. annua varieties against Plasmodium falciparum in vitro in order to determine if synergism will increase the effectiveness of artemisinin in the samples as compared to pure artemisinin. We found that the $\mathrm{IC}_{50}$ of artemisinin in the tea and nonpolar extracts was not significantly different to the $\mathrm{IC}_{50}$ of pure artemisinin. We could show that the year and country of harvest or storage conditions did not have any influence on the activity and that it narrowly followed the concentration of artemisinin in all the extracts. In conclusion, based on these in vitro results, artemisinin seems to be the only active antiplasmodial compound in A. annua.

Key words

Artemisia annua L. - Asteraceae - artemisinin - tea infusion · Plasmodium falciparum

Artemisia annua L. (Asteraceae) contains the well-known antimalarial compound artemisinin (ART). The maceration of A. annua fresh plant material was used in China almost two thousand years before the isolation and identification of ART in the early 1970s, to treat fevers or chills [1]. It is of great importance to note that no resistance against ART has been reported in China despite its use over a very long period of time. Despite the commercialization of ART-based drugs and the use of ART combination therapies (ACTs), local populations of the most affected countries continue to drink tea infusions made from $A$. annua to treat malaria but also for the treatment of other diseases such as HIV [2]. The reason for this can be found in the social sciences - economics and trust. It is inexpensive and in a form that most third world country communities rely on. It is however claimed that synergy between ART and other components in the tea infusion will enhance the activity of ART and make the tea infusion more active than pure ART alone. If true, this could scientifically justify the traditional use. Some studies have already shown that other compounds can improve the antimalarial activity of ART [3] or exhibit some antimalarial activity alone [4].

Our study flows from the recently published WHO position statement on the effectiveness of non-pharmaceutical forms of A. annua against malaria. This statement contains three claims upon which the recommendation of the WHO is based that A. annua in any herbal formulation should not be used to treat malaria. In short the three claims are:

1. The content of ART is variable and overall too low in A. annua. 2. Patients are therefore underdosed which could lead to resistance.

3. Recrudescence is unacceptably high and indicates that potential synergism between ART and other compounds are negligibly low.

The final conclusion drawn from these claims is: "Extensive fundamental and clinical research would be required to demonstrate that non-pharmaceutical forms of $A$. annua, including tea bag, are safe and effective to treat malaria and that their dissemination would not promote the development of ART-resistant parasites" [5].

Our main objective in this study was to test the tea infusions prepared from different $A$. annua varieties against Plasmodium falciparum in vitro in order to determine if synergism will increase the effectiveness of ART in the tea infusions as compared to pure ART. Additionally, we also tested nonpolar extracts from A. annua. To determine if synergism plays a significant role, we prepared tea infusions and chloroform extracts from 16 plants of A. annua and two plants of Artemisia afra Jacq. Ex Willd. (Asteraceae) ( Table 1 ) and tested their in vitro activity against Plasmodium falciparum (3D7). The inclusion of $A$. afra can be considered as a negative control because this plant does not contain ART but possesses other similar chemical constituents [6,7], and it is being used in the treatment of malaria [8]. Table 2 shows the $\mathrm{IC}_{50}$ of the tea infusions and chloroform extracts, the concentration of ART in each sample, and the calculated IC $\mathrm{C}_{50}$ of ART in each sample. From $\odot$ Table 2, it can be seen that the A. annua tea samples and chloroform extracts with the lowest content of ART (samples 10,11, and 12) are the least active against $P$. falciparum $\left(\right.$ IC $_{50}>1.5 \mu \mathrm{g} / \mathrm{mL}$ for the teas and $\mathrm{IC}_{50}>0.500 \mu \mathrm{g} / \mathrm{mL}$ for the chloroform extracts). The $A$. afra teas were inactive at the highest concentration tested $\left(\mathrm{IC}_{50}=>25 \mu \mathrm{g} / \mathrm{mL}\right)$, whereas the $A$. annua teas had an average $\mathrm{IC}_{50}$ of $0.75 \mu \mathrm{g} / \mathrm{mL}$. In these samples, the $\mathrm{IC}_{50}$ of the calculated ART varies between $2.52 \mathrm{ng} / \mathrm{mL}$ and $6.61 \mathrm{ng} / \mathrm{mL}$ with an average of $4.97 \mathrm{ng} / \mathrm{mL}$. This value is close to that found for pure ART ( $5.48 \mathrm{ng} / \mathrm{mL}$ ). Taking into account the inherent variability of the bioassay and sample preparation, there appears to be no significant difference between the $\mathrm{IC}_{50}$ of pure ART and ART in the tea infusion except for sample $1\left(\mathrm{IC}_{50}=2.52 \mathrm{ng} / \mathrm{mL}\right)$. However, the $\mathrm{IC}_{50}$ of pure ART varies between $3.27 \mathrm{ng} / \mathrm{mL}$ and $6.11 \mathrm{ng} / \mathrm{mL}$ from one test series to another. Based on this variation, we can conclude that the $\mathrm{IC}_{50}$ of ART in the tea infusions is similar to that of pure ART.

The $A$. annua chloroform extracts had an average $\mathrm{IC}_{50}$ of $0.18 \mu \mathrm{g} /$ $\mathrm{mL}$, and the calculated ART in these samples had an average $\mathrm{IC}_{50}$ of $5.27 \mathrm{ng} / \mathrm{mL}$. The chloroform extracts therefore follow the same trend as was observed for the tea infusions, in that ART appears to be the only active compound. The A. afra chloroform extracts had an average $\mathrm{IC}_{50}$ of $11.02 \mu \mathrm{g} / \mathrm{mL}$. Despite the fact that this plant does not contain ART, its chloroform extract does however show some antiplasmodial activity albeit in an order of magnitude lower than $A$. annua. This data confirms those previously described [7] and suggests that other compounds in A. afra also exhibit some in vitro antiplasmodial activity. According to these observations, it can be concluded that the A. afra tea is not active against $P$. falciparum in vitro and the in vitro activity of ART in the A. annua tea seems not to be improved by other compounds. 
Table 1 Origin of $A$. annua and A. afra* plant material used in this study.

\begin{tabular}{|c|c|c|c|c|}
\hline Sample & Country of cultivation & Harvest period & Plant parts (dried) & Origin of seeds (breeding program) \\
\hline 1 & South Africa & 1999 & leaves/flowers & Anamed \\
\hline 2 & South Africa & 2002 & leaves/flowers & Anamed \\
\hline 3 & South Africa & 2006 & leaves & Anamed \\
\hline 4 & Tanzania & 2006 & leaves & Anamed \\
\hline 5 & Cameroon & 2007 & leaves & Anamed \\
\hline 6 & Germany & 2007 & leaves & Anamed \\
\hline 7 & Mozambique & 2007 & leaves & Anamed \\
\hline 8 & Germany & 2009 & leaves & Anamed \\
\hline 9 & Germany & 2010 & leaves & Anamed \\
\hline 10 & Belgium & 2009 & leaves & Téi vum Séi \\
\hline 11 & Luxembourg & 2011 & leaves & Téi vum Séi \\
\hline 12 & Luxembourg & 2011 & leaves/flowers & Téi vum Séi \\
\hline 13 & Burundi & 2010 & leaves & Anamed \\
\hline $14^{*}$ & Uganda & 2009 & leaves & Collected \\
\hline 15 & Burundi & 2010 & leaves & Anamed \\
\hline 16 & Cameroon & 2009 & leaves & CIPCRE \\
\hline 17 & Congo & 2010 & leaves & Anamed \\
\hline $18^{*}$ & South Africa & 2011 & leaves & Botanical garden, Univ. of Pretoria \\
\hline
\end{tabular}

Table $2 I C_{50}$ values of the extracts and ART in the different $A$. annua and A. afra t teas and chloroform extracts. Pure ART had an average IC 50 of $5.48 \pm 1.54 \mathrm{ng} / \mathrm{mL}$.

\begin{tabular}{|c|c|c|c|c|c|c|}
\hline \multirow[t]{2}{*}{ Sample } & \multicolumn{3}{|l|}{ Tea infusions } & \multicolumn{3}{|l|}{ Chloroform extracts } \\
\hline & Sample IC $50(\mu \mathrm{g} / \mathrm{mL})$ & ART IC 50 (ng/mL) & {$[$ ART] $(\mu \mathrm{g} / \mathrm{mL})$} & Sample IC $50(\mu \mathrm{g} / \mathrm{mL})$ & ART IC 50 (ng/mL) & {$[$ ART] $(\mu \mathrm{g} / \mathrm{mL})$} \\
\hline 1 & $0.53 \pm 0.09$ & $2.52 \pm 0.32^{*}$ & 13.42 & $0.10 \pm 0.01$ & $5.74 \pm 0.28$ & 152.7 \\
\hline 2 & $0.80 \pm 0.03$ & $5.11 \pm 0.45$ & 17.93 & $0.21 \pm 0.01$ & $6.80 \pm 0.18$ & 118.9 \\
\hline 3 & $0.30 \pm 0.01$ & $4.74 \pm 0.23$ & 71.59 & $0.06 \pm 0.00$ & $7.93 \pm 0.29^{*}$ & 356.2 \\
\hline 4 & $0.53 \pm 0.04$ & $5.02 \pm 0.25$ & 38.39 & $0.13 \pm 0.00$ & $4.12 \pm 0.03$ & 179.6 \\
\hline 5 & $0.36 \pm 0.06$ & $4.26 \pm 1.01$ & 48.78 & $0.06 \pm 0.00$ & $5.45 \pm 0.06$ & 234.5 \\
\hline 6 & $0.38 \pm 0.01$ & $4.94 \pm 0.36$ & 64.31 & $0.03 \pm 0.00$ & $3.30 \pm 0.29$ & 320.7 \\
\hline 7 & $0.55 \pm 0.03$ & $4.19 \pm 0.20$ & 32.15 & $0.10 \pm 0.02$ & $5.13 \pm 0.76$ & 177.2 \\
\hline 8 & $0.32 \pm 0.05$ & $5.23 \pm 0.26$ & 58.24 & $0.05 \pm 0.00$ & $6.45 \pm 0.37$ & 417.4 \\
\hline 9 & $0.39 \pm 0.00$ & $4.67 \pm 0.30$ & 44.82 & $0.06 \pm 0.00$ & $7.09 \pm 0.30$ & 263.1 \\
\hline 10 & $2.69 \pm 0.10$ & $6.61 \pm 2.64$ & 8.44 & $0.79 \pm 0.05$ & $6.18 \pm 0.41$ & 21.18 \\
\hline 11 & $2.32 \pm 0.28$ & $5.41 \pm 0.41$ & 8.36 & $0.52 \pm 0.04$ & $5.18 \pm 0.38$ & 22.82 \\
\hline 12 & $1.70 \pm 0.34$ & $5.27 \pm 0.46$ & 11.14 & $0.50 \pm 0.02$ & $3.26 \pm 0.10^{*}$ & 29.11 \\
\hline 13 & $0.36 \pm 0.01$ & $4.85 \pm 0.31$ & 58.29 & $0.05 \pm 0.00$ & $3.55 \pm 0.15$ & 284.2 \\
\hline $14 \dagger$ & $>25.00$ & nd & nd & $11.66 \pm 0.31$ & nd & nd \\
\hline 15 & $0.27 \pm 0.00$ & $5.20 \pm 0.37$ & 87.02 & $0.06 \pm 0.01$ & $4.62 \pm 0.40$ & 417.6 \\
\hline 16 & $0.25 \pm 0.00$ & $6.15 \pm 0.12$ & 117.2 & $0.05 \pm 0.00$ & $4.07 \pm 0.19$ & 550.3 \\
\hline 17 & $0.27 \pm 0.04$ & $5.30 \pm 0.03$ & 64.09 & $0.06 \pm 0.00$ & $5.44 \pm 0.04$ & 336.7 \\
\hline $18 \dagger$ & $>25.00$ & nd & nd & $10.37 \pm 1.01$ & nd & nd \\
\hline
\end{tabular}

nd = not detected; ${ }^{*}$ Denotes a significant difference $(p<0.005)$ with the $I_{50}$ value of pure ART

We do however need to be very careful in interpreting these findings. This analysis excluded the possibility that there are any obvious or easy to find compounds with direct activity against a specific life cycle phase of $P$. falciparum. There are however numerous points to consider, for example:

1. Due to the availability of A. annua we used relatively old plant material ( $>1$ year) as opposed to the recommendation that fresh plant material should be used. Antiplasmodial compounds such as pyrethrins [9] which are known to be present in A. annua [10] and are known to be photosensitive would be degraded in the material that we used. Upon testing all the samples for the presence of these compounds, we could not detect any (data not shown).

2. Our bioassay targets the erythrocyte phase of the parasite, hence any potentially active compounds against other phases of the life cycle will not be detected.
3. The analysis does not take into account that the tea infusion may contain "prodrugs" - compounds that become active only after metabolization.

In conclusion we investigated the claim that synergism enhances the activity of Artemisia tea. Our results indicate that in the bioassay used, ART appears to be the only antiplasmodial compound in the tea and the chloroform extracts. Very recently, two other studies were published reporting on the activity of the A. annua tea infusion against $P$. falciparum. In the first one [11], they found that the tea infusions were up to three times more active compared to ART alone against chloroquine-sensitive (D10) and -resistant (W2) strains, while in the second one [12], they found that no synergism occurred and that the infusion was equally active to ART alone against field isolates of $P$. falciparum (chloroquine-resistant). Our study confirms the finding in [12] and expands on it by the inclusion of 16 different $A$. annua samples and testing of 
their tea infusions and nonpolar extracts against chloroquinesensitive strains of $P$. falciparum. Although all three studies ([11, 12], current study) show similarities (tea infusions being tested) and differences (different $P$. falciparum strains used, different quantification techniques used to quantify ART in tea infusions), the overall results are remarkably similar with one study leaning towards synergism [11], while the other two ([12], current study) lean towards the tea infusion having no or little synergistic effect. However, before we can claim that there is (no) synergism occurring in the tea infusion, we have to test the above-mentioned points, and particularly, in vivo assays have to be conducted.

\section{Materials and Methods}

$\nabla$

- Table 1 gives the origin of all the plant material used in this study. All plant material obtained from Anamed was identified by Dr. Hans-Martin Hirt (Anamed International). Samples 10-12 were developed by a commercial gardening center in Luxemburg, Téi vum Séi, and was certified by the Ministry of Agriculture of Luxemburg. Sample 16 was certified by CIPCRE as A. annua. A. afra (sample 14) was collected in Uganda in 2009, and sample 18 in the Botanical garden of the University of Pretoria, South Africa in 2011.

The tea samples were prepared according to the method previously described [13]. The chloroform extracts were prepared by extracting $200 \mathrm{mg}$ of dried plant material with $5 \mathrm{~mL}$ of chloroform. These samples were sonicated for $30 \mathrm{~min}$, filtered and transferred into HPLC vials (duplicate). The chloroform was evaporated under nitrogen gas. All dried extracts were weighed, and one sample of each duplicate was evaluated for the antiplasmodial activity testing. The duplicate samples were kept for ART quantification which took place on the same day as the antiplasmodial testing.

The ART concentration was determined as previously described using HPLC-ELSD analysis [14]. The antiplasmodial bioassays were performed on the erythrocyte phase of the parasite Plasmodium falciparum 3D7 (chloroquine-sensitive strain) as previously described [7]. Pure ART (Sigma-Aldrich, 98\% purity, cat. nm. 361593-100MG) was used as a positive control. The medium containing parasitized red blood cells was used as a positive growth control and the medium alone as a negative growth control. The samples were dissolved in DMSO (for the chloroform extracts) or in $10 \%$ ethanol (for the tea infusions) in order to obtain a stock concentration of $5 \mathrm{mg} / \mathrm{mL}$. References and samples were then diluted with medium in a series of twofold dilutions (tea) or fourfold dilutions (chloroform extract).

\section{Acknowledgements}

$\nabla$

The authors gratefully thank the Belgian National Fund for Scientific Research (FNRS) (grant 3.4533.10).

\section{Conflict of Interest \\ $\nabla$}

The authors declare no conflicts of interest.

\section{References}

1 De Ridder S, Van der Kooy F, Verpoorte R. Artemisia annua as a self-reliant treatment for malaria in developing countries. J Ethnopharmacol 2008; 120 : 302-314

2 Lubbe A, Seibert I, Klimkait T, Van der Kooy F. Ethnopharmacology in overdrive: the remarkable anti-HIV activity of Artemisia annua. J Ethnopharmacol 2012; 141: 854-859

3 Elford BC, Roberts MF, Phillipson JD, Wilson RJ. Potentiation of the antimalarial activity of qinghaosu by methoxylated flavones. Trans R Soc Trop Med Hyg 1987; 81: 434-436

4 Liu K, Yang SL, Roberts MF, Elford BC, Phillipson JD. Antimalarial activity of Artemisia annua flavonoids from whole plants and cell cultures. Plant Cell Rep 1992; 11: 637-640

5 WHO Report, 2012. WHO position statement on effectiveness of nonpharmaceutical forms of Artemisia annua L. against malaria. Available at http://www.who.int/malaria/position_statement_herbal_remedy_ artemisia_annua_l.pdf; Assessed November 19, 2012

6 Van der Kooy F, Verpoorte R, Meyer JJM. Metabolomic quality control of claimed anti-malarial Artemisia afra herbal remedy and A. afra and $A$. annua plant extracts. S Afr J Bot 2008; 74: 186-189

7 Liu NQ Cao M, Frédérich M, Choi YH, Verpoorte R, Van der Kooy F. Metabolomic investigation of the ethnopharmacological use of Artemisia afra with NMR spectroscopy and multivariate data analysis. J Ethnopharmacol 2010; 128: 230-235

8 Liu NQ Van der Kooy F, Verpoorte R. Artemisia afra: A potential flagship for African medicinal plants? S Afr J Bot 2008; 75: 185-195

9 Hata Y, Zimmermann S, Quitschau M, Kaiser M, Hamburger M, Adams M. Antiplasmodial and antitrypanosomal activity of pyrethrins and pyrethroids. J Agric Food Chem 2011; 59: 9172-9176

10 Singh A, Sarin R. Pyrethins from in vivo and in vitro cultures of Artemisia annua. Indian J Environ Sci 2011; 15: 35-37

11 De Donno A, Grassi T, Idolo A, Guido M, Papadia P, Caccioppola A, Villanova L, Merendino A, Bagordo F, Fanizzi FP. First-time comparison of the in vitro antimalarial activity of Artemisia annua herbal tea and artemisinin. Trans R Soc Trop Med Hyg 2012; 106: 696-700

12 Rocha e Silva LF, Melillo de Magalhães P, Costa MRF, das Graças Costa Alecrim M, Chaves FCM, de Freitas Hidalgo A, Pohlit AM, Vieira PPR. In vitro susceptibility of Plasmodium falciparum Welch field isolates to infusions prepared from Artemisia annua L. cultivated in the Brazilian Amazon. Mem Inst Oswaldo Cruz 2012; 107: 859-866

13 Van der Kooy F, Verpoorte R. The content of artemisinin in the Artemisia annua tea infusion. Planta Med 2011; 77: 1754-1756

14 Liu NQ Choi YH, Verpoorte R, Van der Kooy F. Comparative quantitative analysis of artemisinin by chromatography and qNMR. Phytochem Anal 2010; 21: 451-456

received November 21, 2012

revised January 29, 2013

accepted February 8, 2013

\section{Bibliography}

Dol http://dx.doi.org/10.1055/s-0032-1328324

Published online March 19, 2013

Planta Med 2013; 79: 468-470

(C) Georg Thieme Verlag KG Stuttgart · New York · ISSN 0032-0943

\section{Correspondence}

\section{Dr. Frank van der Kooy}

Centre for Complementary Medicine Research

University of Western Sydney

Locked Bag 1797

Penrith

NSW 2751

Australia

Phone: + 61246203136

Fax: + 61246203291

f.vanderkooy@uws.edu.au 